\title{
The Study of Standardization for a Korean Dizziness Handicap Inventory for Patient Caregivers
}

\author{
Tae-Hun Kim ${ }^{1 *}$, Heung Eog Cha ${ }^{2 *}$, Jong-Geun Lee ${ }^{1}$, Gi Jung Im $^{1}$, Jae-Jun Song ${ }^{1}$, Shin Hye Kim³, \\ Il Joon Moon ${ }^{4}$, Young Ho Kim ${ }^{5}$, Jae Yong Byun ${ }^{6}$, and Sung-Won Chae \\ ${ }^{I}$ Department of Otorhinolaryngology-Head and Neck Surgery, Korea University College of Medicine, Seoul; and \\ ${ }^{2}$ Department of Otorhinolaryngology-Head and Neck Surgery, Gil Medical Center, Gachon University of Medicine and Science, Incheon; and \\ ${ }^{3}$ Department of Otorhinolaryngology-Head and Neck Surgery, Inje University College of Medicine, Haeundae Paik Hospital, Busan; and \\ ${ }^{4}$ Department of Otorhinolaryngology-Head and Neck Surgery, Samsung Medical Center, \\ Sungkyunkwan University School of Medicine, Seoul; and ${ }^{5}$ Department of Otorhinolaryngology-Head and Neck Surgery, \\ Seoul National University Boramae Medical Center, Seoul National University College of Medicine, Seoul; and \\ ${ }^{6}$ Department of Otorhinolaryngology-Head and Neck Surgery, Kyung Hee University Hospital at Gangdong, Kyung Hee University \\ School of Medicine, Seoul, Korea
}

\section{한국어 번역판 소아 어지럼장애 척도의 표준화 연구}

김태훈 ${ }^{*} \cdot$ 차흥억 ${ }^{*} \cdot$ 이종근 ${ }^{1} \cdot$ 임기정 $^{1} \cdot$ 송재준 $^{1} \cdot$ 김신혜 $^{3} \cdot$ 문일준 $^{4} \cdot$ 김영호 $^{5} \cdot$ 변재용 ${ }^{6} \cdot$ 채성원 $^{1}$

고려대학교 의과대학 이비인후과학교실, ${ }^{1}$ 가천의과학대학교 길병원 이비인후과학교실,

인제대학교 의과대학 해운대백병원 이비인후과학교실, ${ }^{3}$ 성균관대학교 의과대학 삼성서울병원 이비인후과학교실, ${ }^{4}$

서울대학교 의과대학 보라매병원 이비인후과학교실, ${ }^{5}$ 경희대학교 의과대학 강동경희대학교병원 이비인후과학교실 ${ }^{6}$

\author{
Received June 14, 2019 \\ Revised July 23, 2019 \\ Accepted August 2, 2019 \\ Address for correspondence \\ Sung-Won Chae, MD, PhD \\ Department of Otorhinolaryngology- \\ Head and Neck Surgery, \\ Korea University \\ College of Medicine, \\ 148 Gurodong-ro, Guro-gu, \\ Seoul 08308, Korea \\ Tel $+82-2-2626-3186$ \\ Fax $+82-2-868-0475$ \\ E-mail schae@kumc.or.kr \\ *These authors contributed equaly to \\ this work.
}

Background and Objectives Several questionnaires had been developed to assess the handicap due to dizziness. The questionnaires for adults were used and these had been translated into Korean with validity and reliability. However, there is no Korean translation of dizziness inquiry form owing to the little concern of the pediatric dizziness. The objective of this study was to determine the reliability and validity of a Korean Dizziness Handicap Index for Patient Caregivers (KDHI-PC), and revealed the factor analysis of this index.

Subjects and Method We sampled the 24 pediatric patients who had dizziness-related symptoms and visited the hospitals. The patients completed a questionnaire (DHI-PC) that had been translated and reverse translated into Korean. The results of this investigation were analyzed using exploratory factor analysis, Cronbach's $\alpha$ coefficient and internal consistency reliability.

Results By exploratory factor analysis, KDHI-PC was divided into two scales. This questionnaire showed a good internal consistency (Cronbach's $\alpha=0.945$ ). All items had good item-total correlations.

Conclusion The KDHI-PC is a reliable tool for evaluating the dizziness of pediatric patients. Korean J Otorhinolaryngol-Head Neck Surg 2019;62(8):442-7

Key Words Children · Dizziness · Standardization · Questionnaire.
서 론

어지럼(dizziness)이란 실신 전의 아찔한 느낌, 자세의 불안
정, 혹은 머리가 멍한 상태를 뜻하는 용어이다. 이러한 어지 럼 및 현훈은 의료기관을 방문하게 하는 가장 흔한 증상 중 하나로 17 39\%의 유병률로 보고되고 있다.1) 어지럼 환자의

This is an Open Access article distributed under the terms of the Creative Commons Attribution Non-Commercial License (https://creativecommons.org/licenses/by-nc/4.0) which permits unrestricted non-commercial use, distribution, and reproduction in any medium, provided the original work is properly cited. 
신속하고 정확한 진단은 초기 환자 진료에서 중요한 부분을 차지하나 대부분의 어지럼 검사들은 검사 시간과 비용 문제 로 한계점을 나타낸다. ${ }^{2}$ 이에 반해 어지럼 설문지는 경제적이 고 접근성이 용이하여 다양하게 사용되고 있다. ${ }^{3)}$

소아의 어지럼은 성인과 마찬가지로 유병률이 높다. 1년 안 에 어지럼을 한 번 이상 느낀 소아의 비율이 전체의 $15 \%$ 라 고 보고된 바가 있다. ${ }^{4}$ 하지만, 소아는 균형감각의 발달이 완 전하지 못한 시기이므로 어지럼의 위험성이 성인보다 더 높 다. 그러므로 소아에 대한 어지럼 평가는 중요하지만 현재 사 용되는 설문지들은 성인을 대상으로 하고있어 소아에게 바 로 적용하는 것은 어렵다. 대표적 어지럼 설문지인 한국어판 어지럼장애 척도(Korean Dizziness Handicap Inventory, K$\mathrm{DHI}$ )에서 F3 문항의 ‘출장, 여행', F6 문항의 ‘외식 등의 사회 생활과 같은 용어와 한국어판 활동특이적 균형자신감 척도 (Korean Activities-specific Balance Confidence Scale)의 '승용차 타고 내릴 때'와 '혼잡한 백화점' 등의 용어는 성인 기 준의 단어들로 소아 환자는 이러한 설문지를 완성할 수 없게 구성되어 있다. ${ }^{5)}$

설문지는 증상의 객관화에 있어서 중요한 요소이나, 국내 에서 사용되고 있는 설문지들을 소아에게 바로 적용시키기 에는 한계가 있다. 하지만 국외에서는 소아를 대상으로 한 다 양한 설문지들이 개발되었고, Dizziness Handicap IndexPatient Caregiver(DHI-PC)나 Pediatric Vestibular Symptom Questionnaire(PVSQ) 등이 실제 임상에서 쓰이고 있다. $\left.{ }^{67}\right)$ 이에 본 연구에서는 소아 어지럼 설문지로 보편적으로 쓰이는 $\mathrm{DHI}-\mathrm{PC}$ 를 한국어로 번역하고 임상환자들에게 적용하여 그 신뢰도를 확인하고자 하였으며, 이를 통하여 소아 어지럼 환 자의 증상의 객관화와 표준화를 목표로 하였다.

\section{대상 및 방법}

\section{어지럼 척도의 특징과 선정}

\section{DHI-PC}

DHI-PC는 2015년 McCaslin 등ㄱㅇㅣ 고안한 설문지로, 13세 이하의 소아 어지럼의 일상생활 장애를 평가를 위해 만들어 졌으며 보호자가 작성을 하도록 설계되었다. 설문 문항은 4점 척도(0: 전혀 없다, 2: 가끔 그렇다, 4: 항상 그렇다)로 평가되 었고 21개의 문항, 총점 84점으로 이뤄져 있다. DHI-PC 문항 설계를 위해 청각학 전문가와 어지럼 소아의 부모가 협의하 여 소아 어지럼과 관련된 40개의 문항을 만든 후, 항목-척도 피어슨 상관성(item-total Pearson correlation)을 이용하여 총 점수와 불일치하는 문항 15 개를 제외하였다. 선택된 25 개
의 문항의 Cronbach's $\alpha$ 값은 0.93으로 높은 신뢰도를 보였다. 25개의 문항 중에 내적 일관성 신뢰도(internal consistency reliability) 분석을 시행하여 항목-척도 상관성의 수치가 0.3 이하인 4 개의 문항을 제거하여, 최종적으로 21 개의 문항이 선택되었다. ${ }^{7)}$

\section{번역절차}

본 연구는 DHI-PC의 원저자에게 한국어 번역판 개발에 대해 동의를 얻고 시행되었다. 이비인후과 의사 4 명을 포함한 전문가 집단에 의하여 진행되었다. 기본적인 절충 시 모든 의 문형의 문장의 종결은 ' 니까?'로 통일하였으며, 'Your child' 는 '자녀'로 번역하였다. 단어 사용이나 철자법의 확인을 위해 '네이버(www.naver.com)' 국어 및 영한 사전을 사용하였다. 이후 영어와 한국어에 능통한 2명의 번역자들이 역번역을 실 시하였다. 역번역본과 원본을 비교하여 내용이 불일치 할 경 우, 재검토를 시행하여 최종 번역형태인 $\mathrm{KDHI}-\mathrm{PC}$ 를 완성하 였다(Table 1).

\section{자료수집}

2018년 12월부터 2019년 3월까지 고려대학교 구로병원, 고 려대학교 안암병원, 인제대학교 해운대백병원, 가천의과학대 학교 길병원, 성균관대학교 삼성서울병원, 서울대학교 보라 매병원, 경희대학교 강동경희대학교병원 외래로 내원한 어지 럼을 주소의 소아를 대상으로 하였다. 소아의 연령은 DHI$\mathrm{PC}$ 와 동일하게 만 5 세부터 만 13세 미만을 기준으로 하였다. 설문지 작성은 상기 기간 동안 내원한 모든 어지럼 소아와 그 보호자를 대상으로 하였다. 24명의 어지럼을 호소하는 소아 를 대상으로 하여 설문지 작성이 이뤄졌다. 회수된 설문지에 서 환자의 의무기록 사항, 진단명, 기저질환, 나이, 성별, 문항 별 점수를 확인하였고 설문지 답안의 정확도가 부족하거나 미비 답안이 포함된 설문지는 분석에서 제외하였다.

모든 환자는 병력청취, 신체검진을 시행하였으며 첫 외래 방문 시점 기준으로 $\mathrm{KDHI}-\mathrm{PC}$ 를 작성하였다. 설문지는 환 자 보호자가 작성하였으며 문항에 대한 이해가 부족한 경우 검사자가 보충 설명을 제공하였다. 설문지 작성 후 정확한 진 단을 위해 필요한 경우 이비인후과 전문의 판단하에 추가적 검사를 시행하였다.

\section{문항-영역 분류}

$\mathrm{KDHI}-\mathrm{PC}$ 는 21개의 문항으로 구성되어 있으며, 영역(scale) 의 분할이 되지 않은 단순 항목들로만 이뤄진 설문지이다. 이 에 탐색적 요인 분석(exploratory factor analysis)를 이용해 문항의 영역 분류를 시행하였다. 요인 분석에는 Harris-Kai- 
$\operatorname{ser}$ 방법을 사용하여 인자회전을 한 결과를 기준으로 제시하 였으며 추출되는 인자들의 특성과 각 요인 수에 따른 해석을 고려하여 분류하였다(Table 1).

\section{신뢰도 분석}

본 연구는 IBM SPSS version 20.0(IBM Corp, Armonk, $\mathrm{NY}, \mathrm{USA}$ )을 이용하여 자료 분석을 하였다. 각 문항은 4점 척 도로 구성된 서열척도로서 Spearman 상관계수를 이용하였고

Table 1. The Korean Dizziness Handicap Inventory for Patient Caregivers

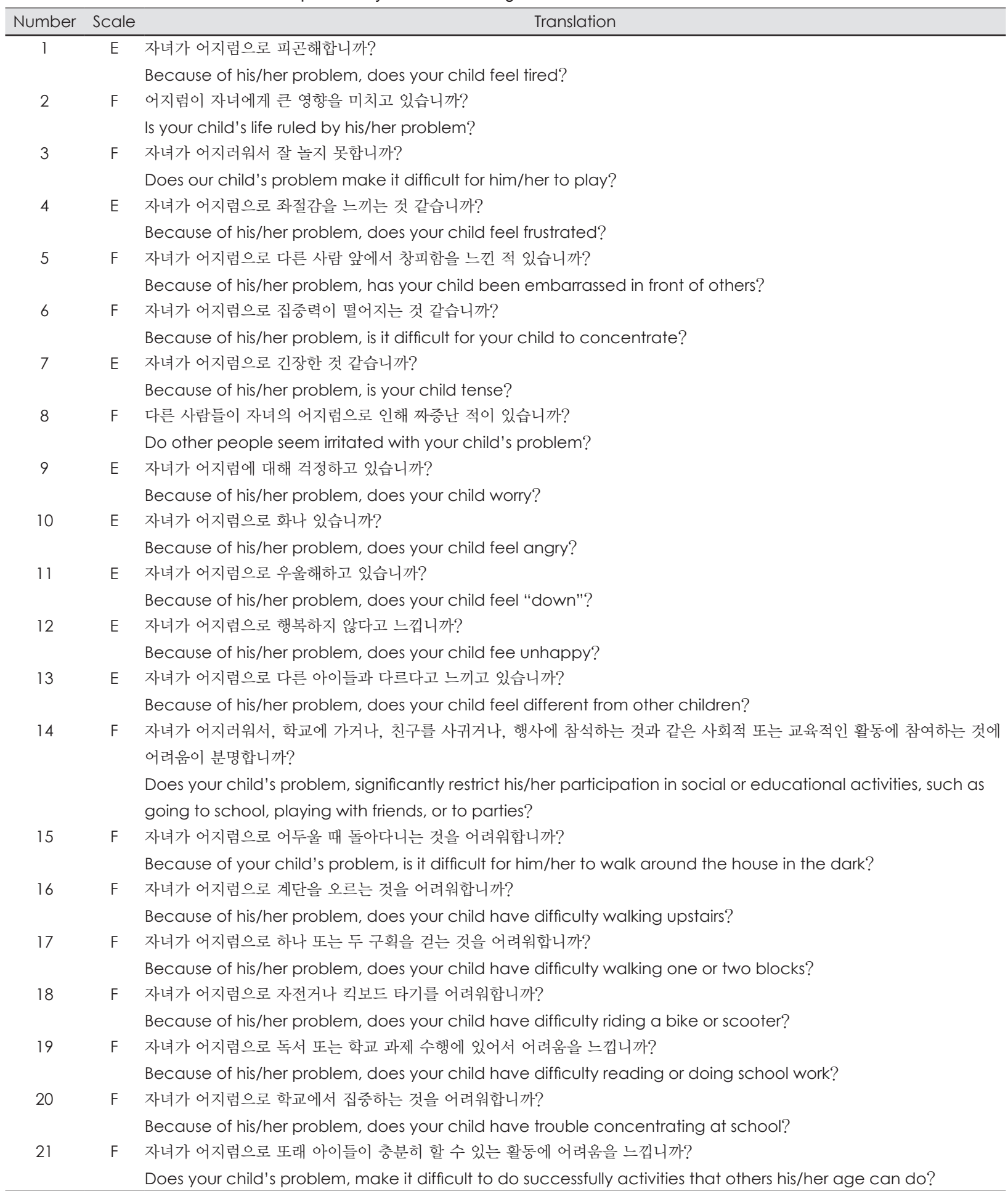


그 이외의 경우에는 Pearson 상관계수를 사용하였다. KD$\mathrm{HI}-\mathrm{PC}$ 한국판 번역본의 신뢰도 분석을 위하여 Cronbach's $\alpha$ 값을 계산하였으며 해당 값이 0.7 이상일 경우 신뢰도가 있 는 것으로 판정하였다. 개별 항목의 내적 일관성 신뢰도(internal consistency reliability)를 평가하여 0.3 이하의 항목 은 최종 설문지에서 제외하였다.

\section{결 과}

\section{탐색적 요인분석}

21항목의 설문지는 2개의 요인(factor)로 분류되었으며, 21 개 항목의 총 설명 분량은 $64.38 \%$ 였다. 각 요인별 설명 분량 을 살펴보면 제1요인이 37.04\%이고 제2요인이 $27.34 \%$ 로 제 1 요인이 더 높았다. 각 요인별로 묶인 문항들의 공통된 특징 을 살펴보고 $\mathrm{DHI}$ 의 분류를 고려하여 요인에 대한 명명을 시 행하였다. 제 1 요인은 총 13 문항으로 '계단 오르기', '자전거 타 기', ‘과제 수행' 등 기능적인 부분을 반영하는 것을 알 수 있 다. 이에 기능적 영역(functional scale)으로 명명하였다. 제2 요인은 총 8문항으로 '좌절감', '긴장', '걱정' 등과 같은 감정적 부분을 반영하는 것을 알 수 있다. 이에 정서적 영역(emotional scale)로 구분하였다(Table 2). 이러한 분류를 통하여 기능 적 영역 13 문항, 정서적 영역 8 문항으로 이뤼진 21항목의 설 문지를 완성하였다.

\section{신뢰도 분석}

어지럼 주소로 내원한 13세 이하의 소아를 대상으로 위의 21 개의 문항을 모두 완료한 24 명의 환자의 자료를 이용하여 분석하였다. 정서적 특성, 기능적 특성의 평균은 각각 1.05 , 0.92였으며, 전체 문항의 평균 수치는 0.97이었다(Table 3).

정서적, 기능적 영역의 Cronbach's $\alpha$ 값은 각각 0.910, 0.942 이었고, 총합의 Cronbach's $\alpha$ 값은 0.945이다. 각각의 영역과 총합의 수치들 모두 0.7 이상으로 신뢰할 만한(acceptable, reliable) 수치로 확인되었다(Table 4).

각 항목에 대한 항목-총점 상관성도를 분석하였다. 항목총점 상관도는 각 항목이 전체 설문 점수와 얼마나 관련되어 있는지를 알려주며 0.3 이하의 항목은 관련성이 적다고 판단 하게 되는데, 모든 항목은 0.3 이상의 상관성이 있었다. 항목 7만이 0.36 의 낮은 항목-총점 상관성을 보였고, 이 항목을
제거 시 Cronbach's $\alpha$ 가 본래 0.945에서 0.946으로 상승한 것을 확인할 수 있었다(Table 5).

\section{고 찰}

어지럼(dizziness)이란 실신 전의 아찔한 느낌, 자세의 불안 정, 혹은 머리가 멍한 상태를 뜻하는 용어이다. 어지럼의 원 인의 판별은 정확한 병력 청취와 신체 검진이 우선적으로 필 요하다. 그러나 소아는 정확한 병력 청취가 힘들고, 협조가 안될 시 신체 검진 또한 어려운 경우가 있다. 소아 어지럼에 서는 보호자를 통한 객관적인 병력청취와 증상의 중증도를 파악하는 것이 필수적이다. 이러한 필요성에 의거하여 국외 에서는 소아를 대상으로 DHI-PC나 PVSQ 등의 설문지들

Table 2. Exploratory factor analysis of the Korean Dizziness Handicap Inventory for Patient Caregivers

\begin{tabular}{|c|c|c|}
\hline \multirow[b]{2}{*}{ Item } & \multicolumn{2}{|c|}{ Factor loading } \\
\hline & $\begin{array}{l}\text { Factor } 1 \\
\text { function }\end{array}$ & $\begin{array}{l}\text { Factor } 2 \\
\text { emotion }\end{array}$ \\
\hline 1 & & 0.76 \\
\hline 2 & 0.54 & \\
\hline 3 & 0.77 & \\
\hline 4 & & 0.71 \\
\hline 5 & 0.67 & \\
\hline 6 & 0.52 & \\
\hline 7 & & 0.46 \\
\hline 8 & 0.65 & \\
\hline 9 & & 0.81 \\
\hline 10 & & 0.91 \\
\hline 11 & & 0.77 \\
\hline 12 & & 0.77 \\
\hline 13 & & 0.77 \\
\hline 14 & 0.68 & \\
\hline 15 & 0.88 & \\
\hline 16 & 0.94 & \\
\hline 17 & 0.67 & \\
\hline 18 & 0.82 & \\
\hline 19 & 0.76 & \\
\hline 20 & 0.74 & \\
\hline 21 & 0.80 & \\
\hline Total eigenvalues & 7.78 & 5.74 \\
\hline$\%$ of variance & 37.04 & 27.34 \\
\hline Cumulative $\%$ of variance & 37.04 & 64.38 \\
\hline
\end{tabular}

Table 3. Statistics of the Korean Dizziness Handicap Inventory for Patient Caregivers

\begin{tabular}{ccccccccc}
\hline Scale & Items & $\mathrm{n}$ & Mean & Variance & Median & Skewness & Kurtosis \\
\hline Emotion & 8 & 24 & 1.05 & 1.92 & 0.00 & 0.95 & -0.35 & 0.06 \\
Function & 13 & 24 & 0.92 & 1.69 & 0.00 & 1.11 & 0.06 \\
\hline Total & 21 & 24 & 0.97 & 1.78 & 0.00 & 1.04 & -0.13 \\
\hline
\end{tabular}


Table 4. Reliability of the Korean DHI-PC

\begin{tabular}{ccc}
\hline DHI-PC scale & Items & Cronbach's $\alpha$ \\
\hline Emotion & 8 & 0.910 \\
Function & 13 & 0.942 \\
\hline Total & 21 & 0.945
\end{tabular}

DHI-PC: dizziness handicap inventory for patient caregivers

Table 5. Validity of the Korean Dizziness Handicap Inventory for Patient Caregivers

\begin{tabular}{cccc}
\hline Number & Scale & Item-total correlation & $\begin{array}{c}\text { Cronbach's } \alpha \\
\text { if item deleted }\end{array}$ \\
\hline I & E & 0.432 & 0.946 \\
2 & F & 0.578 & 0.943 \\
3 & $F$ & 0.648 & 0.942 \\
4 & E & 0.797 & 0.940 \\
5 & F & 0.864 & 0.940 \\
6 & F & 0.514 & 0.944 \\
7 & E & 0.360 & 0.946 \\
8 & $F$ & 0.538 & 0.944 \\
9 & E & 0.443 & 0.947 \\
10 & E & 0.719 & 0.941 \\
11 & E & 0.760 & 0.941 \\
12 & E & 0.715 & 0.941 \\
13 & E & 0.715 & 0.941 \\
14 & $F$ & 0.477 & 0.945 \\
15 & $F$ & 0.714 & 0.941 \\
16 & $F$ & 0.801 & 0.940 \\
17 & $F$ & 0.755 & 0.941 \\
18 & $F$ & 0.822 & 0.940 \\
19 & $F$ & 0.648 & 0.942 \\
20 & $F$ & 0.652 & 0.942 \\
21 & $F$ & 0.843 & 0.939 \\
\hline
\end{tabular}

E: emotional, F: functional

이 실제 임상에서 널리 이용되고 있다. ${ }^{67}$

본 논문은 $\mathrm{DHI}-\mathrm{PC}$ 를 번역하여, 국내에서도 객관적인 어 지럼 평가가 소아에게 이뤄질 수 있도록 도움을 주고자 하였 다. 이에 원저자들의 동의를 얻고, 이후 이비인후과 의사 4명 을 포함한 전문가 집단에 의하여 번역을 시행하였고 실제 어 지럼 소아환자에게 적용하였다.

$\mathrm{DHI}-\mathrm{PC}$ 는 요인 분석을 시행하지 않아 영역(scale) 분류가 되지 않은 상태였다. 본 논문에서는 탐색적 요인분석을 통하 여 설문 항목의 영역 분류를 하였으며, 최종적으로 $\mathrm{KDHI}-$ $\mathrm{PC}$ 에서는 13 개의 기능적 영역과 8 개의 정서적 영역으로 분 류하였다. 대표적 어지럼 설문지인 DHI에서는 9개의 감정적 영역과 10 개의 기능적 영역 그리고 6 개의 신체적 영역으로 구 성되어 있는데, 이중 신체적(physical) 영역을 대변하는 항목 이 DHI-PC에는 없다. DHI에서 신체적 영역은 항목 1. "Does looking up increase your problem?”이나 항목 13. “Does turning over in bed increase your problem?"과 같이 증상 의 강도 변화를 묻는 항목으로 구성이 된다. 이러한 항목은 소아 환자에서는 파악하기 쉽지 않다. DHI-PC 초기항목 구 성에서 신체적 영역으로 분류 될 수 있는 "Does your child use a great deal of effort to keep his/her balance?"나 “Is your child's balance unpredictable?"과 같은 항목이 있었 다. 하지만 이 항목들은 항목-총점 상관도가 0.3 이하로 낮 아 최종 설문지에서 탈락하였다.

각각의 항목은 영역 분류에 합당한 지문을 갖고 있었다. Factor 1 항목들은 어지럼으로 일상생활에 지장이 가는 상 황에 대한 항목들이 주로 포함된다. 하지만, 설문지 5 번 항목 은 '창피함'이라는 감정을 대변하는 단어가 들어가 있고 이는 Factor 2에 좀 더 합당한 단어로 생각된다. 하지만 설문지 5 번 항목은 Factor 1 function 0.67점으로 기능적 영역으로 분류되었다. 환자들은 이 항목을 기능적인 문제로 생각했다 는 의미이다. 이는 '다른 사람 앞에서'라는 문장에 의한 것으 로 생각된다. '다른 사람 앞에서'라는 문장은 '다른 사람 앞에 서 무언가 잘 못 했다.라는 의미를 함축하고 있고 이로 인해 창피함을 느꼈을 것이라고 생각해 볼 수 있다. 창피함이 개인 적 감정이 아니라 기능적 능력 저하의 결과물로 인식되어 결 론적으로 기능적 영역으로 분류되었다.

영역 분류 후에 신뢰도 분석을 시행하였고, 2 개 영역의 Cronbach's $\alpha$ 값과 총합의 Cronbach's $\alpha$ 값은 0.7 이상으로 신뢰 할 만한 신뢰도를 보였다. 또한 두 영역이 각각 0.9 이상으로 훌륭한(excellent) 신뢰도를 보였다.

항목-총점 연관성에서는 모든 항목에서 0.3 이상의 연관 성을 보였다. 항목 7번만이 0.360 로 낮은 수치를 보였다. 항 목 7은 “자녀가 어지럼으로 긴장한 것 같습니까?”의 내용으 로 긴장의 대상이나 상황이 명확히 주어지지 않아 문맥 파악 의 어려움이 있었을 것으로 생각된다. 위 항목을 삭제할 시 Cronbach's $\alpha$ 가 0.946으로 상승한 것을 알 수 있다. 이에 상 기 항목을 삭제하여 설문지의 신뢰도를 확보하는 것과 동시 에 항목 점수를 5점으로 수정한다면 총 100점 스케일의 설 문지가 완성되기 때문에 설문지 평가의 용이성까지 확보할 수 있을 것으로 생각된다. 만약 항목 7을 유지한다고 하면, "자녀 가 어지럼이 있을 때 긴장한 것 같습니까?”와 같은 번역 수정 을 통해 긴장 시기에 대한 명시가 필요할 것으로 생각된다.

21 개의 항목으로 한국어 번역판 소아 어지럼장애 척도 $(\mathrm{KD}-$ $\mathrm{HI}-\mathrm{PC})$ 를 구성 시 충분한 신뢰도를 갖고 있음을 확인 할 수 있었다. 다만, 24 명의 적은 환자들을 대상으로 이뤄진 설문지 평가이므로 추후 더 많은 소아를 대상으로 연구하는 것이 필 요할 것으로 생각되며, 환자군의 지속적인 경과 관찰을 통한 검사-재검사 상관 지수를 확인하는 것도 신뢰도 확인에 도움 
을 줄 것으로 생각된다. ${ }^{8}$ 설문지를 진행했던 소아들에게 추 가적 검사를 진행하여 준거타당도를 검증하는 것도 타당성을 판별하는 데 도움을 줄 수 있을 것으로 생각되나, 검사 협조 가 어려운 소아의 특성상 제한점이 있을 것으로 생각된다.

이 논문에서는 $\mathrm{DHI}-\mathrm{PC}$ 를 한국어로 번역하고 항목들의 영역 분류와 신뢰도 평가를 하였다. 향후 $\mathrm{KDHI}-\mathrm{PC}$ 를 통해 국내 소아 어지럼에서의 객관적 접근과 상호 결과 비교에 많 은 도움을 줄 것으로 생각된다.

\section{ORCID}

Sung Won Chae

https://orcid.org/0000-0001-6401-352X

\section{REFERENCES}

1) Kroenke K, Mangelsdorff AD. Common symptoms in ambulatory care: Incidence, evaluation, therapy, and outcome. Am J Med 1989; 86(3):262-6.

2) Jacobson GP, Newman CW. The development of the Dizziness
Handicap Inventory. Arch Otolaryngol Head Neck Surg 1990;116 (4):424-7.

3) Honrubia V, Bell TS, Harris MR, Baloh RW, Fisher LM. Quantitative evaluation of dizziness characteristics and impact on quality of life. Am J Otol 1996;17(4):595-602.

4) Russell G, Abu-Arafeh I. Paroxysmal vertigo in children--an epidemiological study. Int J Pediatr Otorhinolaryngol 1999;49 Suppl 1:S105-7.

5) Han GC, Lee EJ, Lee JH, Park SN, Lee HY, Jeon EJ, et al. The study of standardization for a Korean adaptation of self-report measures of dizziness. J Korean Bal Soc 2004;3(2):307-25.

6) Pavlou M, Whitney S, Alkathiry AA, Huett M, Luxon LM, Raglan E, et al. The Pediatric Vestibular Symptom Questionnaire: A validation study. J Pediatr 2016;168:171-7.e1.

7) McCaslin DL, Jacobson GP, Lambert W, English LN, Kemph AJ. The development of the vanderbilt pediatric dizziness handicap inventory for patient caregivers (DHI-PC). Int J Pediatr Otorhinolaryngol 2015;79(10):1662-6.

8) Chu HS, Cho YS, Park SN, Byun JY, Shin JE, Han GC, et al. Standardization for a Korean adaptation of the international outcome inventory for hearing aids: Study of validity and reliability. Korean J Otorhinolaryngol-Head Neck surg 2012;55(1):20-5. 